\title{
Cultura do uso de Softwares Piratas na região Extremo Oeste Catarinense e Noroeste Gaúcho
}

\author{
Andressa Franciele Feiten \\ Centro Universitário Fai \\ Itapiranga, Brasil \\ andressa14.feiten@gmail.com
}

\author{
Juliane Colling \\ Centro Universitário Fai \\ Itapiranga, Brasil \\ juliane@uceff.edu.br
}

\begin{abstract}
The use of software in our daily lives is a routine practice, however, there is a culture of using software that should be paid for, without proper licensing, using software piracy. In this sense, the present work aims to identify whether the population of the extreme west of Santa Catarina and northwest Rio Grande do Sul has knowledge about the concept and risks of pirated software, as well as how to use them. For this, an online questionnaire was used, disseminated through social networks and messaging applications. As a result, it was identified that most respondents know what pirated software is and know the security and legal risks associated with its use, but still use some pirated software. It is concluded that the use of pirated software is part of a deep-rooted culture, requiring long-term information, awareness and digital education actions to intervene in this situation.
\end{abstract}

Resumo - O uso de softwares em nosso dia a dia é uma prática rotineira, no entanto, percebe-se uma cultura de utilização de softwares que deveriam ser pagos, sem o devido licenciamento, utilizando-se da prática de pirataria de software. Neste sentido, o presente trabalho tem por objetivo identificar se a população da região extremo oeste catarinense e noroeste gaúcho possui ciência sobre conceito e riscos do software pirata, bem como se fazem uso destes. Para isso, utilizou-se de um questionário online, divulgado por meio de redes sociais e aplicativos de mensagens. Como resultado, identificou-se que a maioria dos respondentes sabe o que é o software pirata e conhece os riscos de segurança e legais associados ao seu uso, mas ainda assim utiliza alguns softwares piratas. Conclui-se que o uso de softwares piratas faz parte de uma cultura enraizada, sendo necessárias ações de informação, conscientização e educação digital a longo prazo para intervir nesta situação.

Palavras-chave - Pirataria de Software; Riscos da pirataria; Distribuição ilegal; Segurança da Informação.

\section{INTRODUÇÃO}

A tecnologia tem se tornado cada vez mais presente no dia a dia das pessoas, empresas e locais de ensino. Executar múltiplas tarefas se tornou muito fácil com o avanço da tecnologia, entretanto, manter todos os softwares com as devidas licenças se torna algo muito caro, o que faz com que os utilizadores adotem o uso de softwares piratas. Muitas vezes quem adota o uso de software pirata não sabe os riscos e multas que o uso de softwares ilegais podem acarretar (CONSTANCIO, 2013).

O atrativo para a compra destes produtos é o valor bem reduzido em relação aos originais ou muitas vezes distribuídos gratuitamente. A falta de fiscalização para esse crime favorece o ato, um simples download feito em sites com conteúdo pirata já caracteriza pirataria, sendo necessário que medidas sejam aplicadas para sanar isso (TECHSOUP, [s.d.]).

Percebe-se que há uma cultura de uso de software pirata bem presente na sociedade em geral, especialmente quanto ao uso de sistema operacional e pacote de aplicativos de escritório (como o Windows e o Office, por exemplo). É comum ver anúncios em rádios, folders ou mídias sociais de serviços de formatação de computadores à um valor bem reduzido, que certamente não é suficiente para cobrir o valor de uma licença de software proprietário e são raras as vezes em que os usuários estão abertos ao uso de software livre. No entanto, poucas pessoas sabem dos riscos de uso do software pirata, uma vez que a prática é ilegal, além de oferecer riscos à segurança dos dados armazenados no computador.

Neste sentido, o tema abordado neste projeto de pesquisa, realizado no contexto do Programa de Iniciação Científica de uma Instituição de Ensino Superior, aborda o uso de softwares piratas pela população regional. O objetivo da pesquisa é identificar se a população sabe o que é um software pirata, se compreende os riscos de segurança às informações e aspectos legais do uso de softwares piratas, e se faz uso destes.

Considerando-se todas as situações apresentadas, reforça-se a relevância deste trabalho para o contexto regional, sendo que além de realizar o levantamento de informações sobre o uso de softwares piratas em nossa região, a fim de construir um panorama mais claro sobre a situação regional, desenvolverá uma campanha de conscientização sobre os riscos do uso de software pirata em residências e empresas, destacando os aspectos éticos, legais e de segurança da informação. Espera-se com esta ação conscientizar a população regional e contribuir para evitar problemas de multas ou perda de dados causados por uso de software não licenciado. 


\section{REVISÃO TEÓRICA}

Software são programas de computadores com documentação associada. Para que a parte física do computador funcione, é necessário que existam softwares, que são programas que dão vida a máquina, por meios de códigos contidos no software, esses códigos são informações que permitem que o computador, por exemplo, ligue a impressora, imprima um texto, entre outras várias funções exercidas por uma máquina (OKUYAMA; MILETTO; NICOLAO, 2014).

Existem dois tipos de softwares, os genéricos e os sob encomendas. Os softwares genéricos são desenvolvidos para qualquer pessoa que quiser adquirir, porém o sob encomenda, ele é desenvolvido através do pedido e necessidade do cliente, e é desenvolvido com exclusividade (SOMMERVILLE, 2007).

Além desta classificação, a definição dos softwares pode ser classificada como software livre ou software proprietário. O software livre permite a utilização, cópia, compartilhamento e alteração sem restrição, como exemplos pode-se citar os sistemas operacionais Linux e o pacote de aplicativos de escritório LibreOffice. Já o software proprietário é o oposto, ou seja, que possui distribuição e alteração limitadas, por questões de patentes ou registros, exemplo desse software é sistema operacional Microsoft Windows, pacote Microsoft Office, entre outros (OKUYAMA; MILETTO; NICOLAO, 2014).

\section{A) Pirataria de software}

Segundo o Orrico (2004), a pirataria é uma prática muito antiga. $\mathrm{O}$ conceito dessa palavra vem de pilhagem, ou seja roubar o trabalho de outra pessoa, ou tomar propriedade de algo que não o pertence, e assim gerar lucros de trabalhos realizados por outros.

No contexto do desenvolvimento de software, a pirataria trata-se do uso, cópia ou distribuição de programas de computador sem a devida licença para tal, sendo uma prática ilegal na reprodução de um programa de computador, sem a autorização expressa do titular do produto (MAIS DADOS DIGITAL, [s.d.])

De acordo com o site Mais Dados Digital ([s.d.]), a Associação Brasileira de Empresas de Software estima que o uso de softwares piratas gera um prejuízo superior a US\$ 300 bilhões em todo o mundo.Esse prejuízo se reflete no faturamento das empresas que desenvolvem o software, como também na arrecadação de impostos sobre a comercialização destes, de forma que afeta toda a população.

Cabe destacar que no Brasil, o Artigo 184 do Código Penal considera como crime "Violar direitos de autor e os que lhe são conexos" e se enquadra como Crime contra Propriedade Intelectual, com pena de 3 meses a 1 ano de reclusão, podendo ser estendida até 4 anos, dependendo se o autor utilizou o produto para divulgação com benefício financeiro ou não.

A pirataria de software pode ocorrer nos casos de uso de programa de computador sem a correspondente licença. Segundo a lei dos direitos autorais (9.610/1998), quem editar e vender obras sem autorização do seu titular deverá pagar por cada um dos exemplares vendidos. Caso o número de exemplares vendidos não puder ser computado, o transgressor deverá pagar o valor de três mil exemplares, além dos apreendidos (BRASIL, 1998).

Segundo dados da BSA The Software Alliance, aproximadamente $46 \%$ dos programas utilizados no Brasil são piratas, cerca de 30.760 denúncias foram feitas por uso ilegal de software no Brasil até 2015 e 2.720 ações judiciais foram executadas no Brasil por uso ilegal de software a partir desta data. Em 2009 a Diretoria Estadual de Investigações Criminais (DEIC) de Florianópolis cumpriu cerca de 50 mandados de busca e apreensão em empresas do Vale do Itajaí e Norte do estado, dentre esses mandados foram encontrados softwares piratas em 47 empresas, o prejuízo calculado foi de pelo menos $\mathrm{R} \$ 750 \mathrm{mil}$ (BAGUETE, 2009).

Bieger (2018), realizou em seu trabalho final de curso um levantamento do uso de softwares não licenciados no setor público de um município da região, e identificou que nos setores administrativos e escolas municipais 71 computadores se utilizavam de sistema operacional Windows sem a devida licença, e 123 computadores utilizavam o pacote Microsoft Office sem a devida licença. No mesmo estudo, apresenta-se uma estimativa de valor de multa que poderia ser aplicado à esta organização em caso de fiscalização, e considerando-se que a multa pode chegar a 3 mil vezes o valor da licença por computador, o valor total de multa a ser aplicada poderia chegar ao montante de R\$ 803.378.310,00 (oitocentos e três milhões e trezentos e setenta e oito mil e trezentos e dez reais), além de ter que adquirir as licenças dos softwares pirateados que é de R\$ 267.792,77 (duzentos e sessenta e sete mil e setecentos e noventa e dois reais e setenta e sete centavos). O autor da pesquisa destacou também que, ao apresentar os resultados do levantamento e a possível multa que poderia ser aplicada em caso de fiscalização, o gestor municipal ficou surpreso e declarou que desconhecia a situação de uso de softwares não licenciados e que isso poderia gerar multas e riscos à segurança das informações (BIEGER, 2018).

\section{B) Riscos à Segurança}

Além de ser uma prática ilegal, o uso de softwares sem a devida licença pode trazer riscos à segurança das informações. De acordo com a Techsoup Brasil (2019), o uso de software pirata pode causar baixo desempenho das aplicações, tornando o computador mais lento, travar programas em execução, além de deixá-lo muito mais suscetível a invasões, instalação de vírus e demais programas maliciosos, que podem danificar os equipamentos da empresa, expor informações sigilosas ou mesmo leva à perda de dados importantes da empresa.

Em 2017 ocorreu um dos maiores ataques cibernéticos do mundo, quando o software malicioso Wanna Cry infectou mais de 200 mil computadores em cerca de 150 países. Este software "sequestrava" os dados armazenados nos computadores, criptografando-os e exigindo do proprietário um valor em dinheiro para liberar a chave criptográfica de acesso. Muitas pessoas, empresas e órgãos públicos tiveram grandes prejuízos com estes ataques, inclusive em nossa região, sendo que uma grande parte deles utilizavam sistema operacional Windows desatualizado ou sem a devida licença. Neste sentido, reforça-se a importância de que as pessoas tenham 
consciência sobre os softwares que utilizam, a fim de evitar perda de dados relevantes para suas atividades e seu negócio (OLHAR DIGITAL, 2019).

\section{METODOLOGIA}

A presente pesquisa trata-se de um estudo de finalidade qualitativa, que busca averiguar se as pessoas utilizam softwares piratas e se possuem ciência disso. Para tanto, utilizou-se de pesquisa exploratória, a fim de aprofundar conhecimentos sobre o assunto, realizando inicialmente uma revisão bibliográfica, e posterior coleta de dados utilizando-se um formulário online, por fim planejou-se palestrar em instituições para conscientizar os usuários, porém com a presente pandemia de covid-19 isso se tornou inviável, mas deseja-se dar continuidade no primeiro semestre de 2021, para auxiliar na conscientização dos que se dispuseram a responder a pesquisa, foi utilizado uma breve explicação e apresentado problemas decorrentes de softwares piratas conforme Figura 1 e 2 .

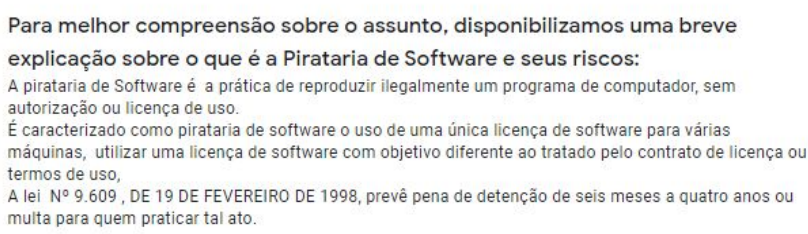

Figura 1 - Breve explicação sobre pirataria de software

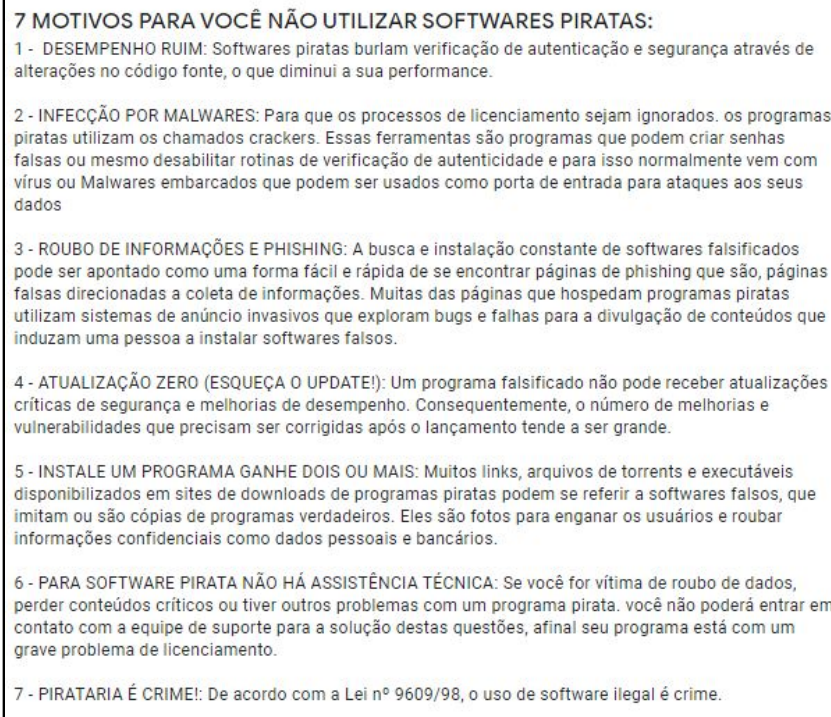

Figura 2 - 7 motivos para não utilizar softwares piratas

\section{RESULTADOS E DISCUSSÃO}

Foi elaborado um questionário, com sete perguntas a respeito do uso de softwares piratas, tinha-se o intuito de coletar dados, o questionário foi respondido por 100 pessoas de forma anônima. A divulgação do questionário foi realizada por meio de redes sociais e grupos de mensagens.

Inicialmente foi questionado aos respondentes se estes sabem o que é a pirataria de software, sendo que o resultado é apresentado na Figura 3.
Você sabe o que é pirataria de software?

100 respostas

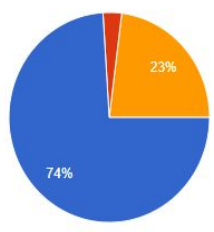

- Sim

Já ouvi falar, mas não tenho clareza do que se trata

Figura 3 - Conhecimento dos respondentes sobre o que é pirataria de software.

Observa-se que grande maioria (74\%) tem conhecimento no assunto, $23 \%$ já havia ouvido, porém não tinha certeza sobre o significado, e poucas pessoas não conheciam o termo. Neste sentido, percebe-se que a maioria das pessoas têm ciência do que se trata a utilização do software pirata, mas ainda há algumas pessoas que não têm clareza sobre o seu significado.

Após esta primeira questão, foi adicionado uma breve explicação sobre $\mathrm{o}$ termo para $\mathrm{o}$ entendimento $\mathrm{e}$ esclarecimento de algumas dúvidas, bem como os riscos e motivos para não usar os softwares sem licenças. Tendo clareza do que se trata, a pergunta seguinte buscou identificar se os respondentes fazem uso de softwares piratas. A Figura 4 apresenta as respostas obtidas.

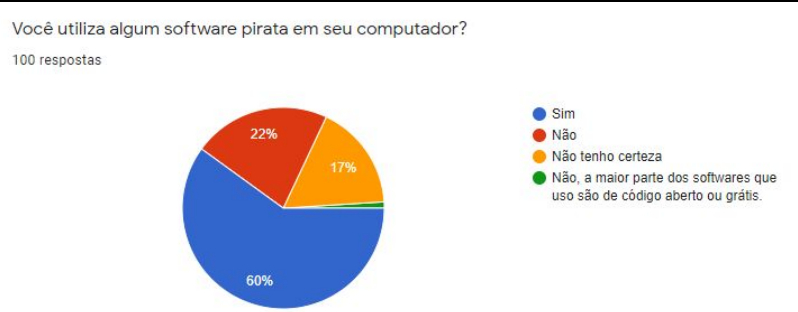

Figura 4 - Uso de software pirata pelos respondentes

Observa-se nas respostas que infelizmente grande parte dos respondentes $(60 \%)$ dos respondentes disseram que sim, utilizam softwares piratas, apesar de a maioria ter ciência do que são. $22 \%$ informaram não fazer o uso de software pirata e $17 \%$ não tem certeza, pelo fato de não ter clareza sobre o assunto ou mesmo por não serem informados no momento da instalação.

A questão seguinte (conforme Figura 5) pergunta aos respondentes que assinalaram afirmativamente para o uso de software pirata, quais softwares costumam ser utilizados, podendo assinalar mais do que uma alternativa.

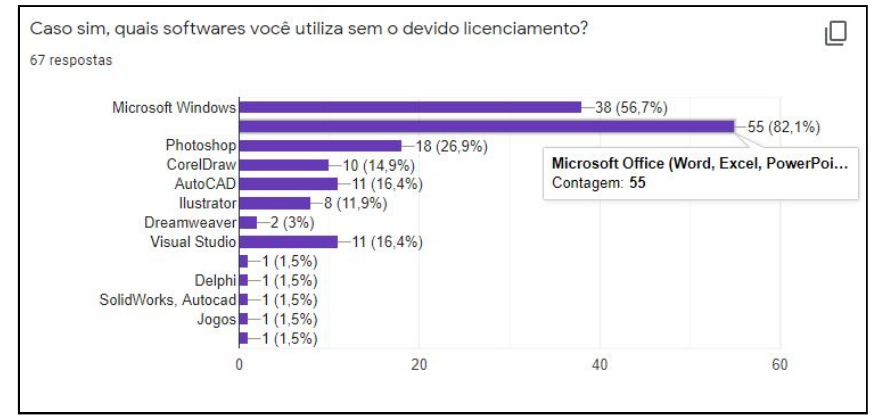


Figura 5: Softwares piratas utilizados pelos respondentes

Observa-se nas respostas que um dos softwares mais pirateados é o pacote Microsoft Office (Word, Excel, PowerPoint), indicado por 55 dos 100 respondentes desta questão, o que representa $82,1 \%$ das respostas. Em seguida, indica-se o sistema operacional Microsoft Windows (38 respostas), Photoshop (18 respostas) e Visual Studio (11 respostas), e outros softwares com menor número de usuários.

A próxima questão foi realizada a fim de identificar se as pessoas instalam estes software de maneira consciente sobre sua procedência ilegal, conforme vemos na Figura 6.

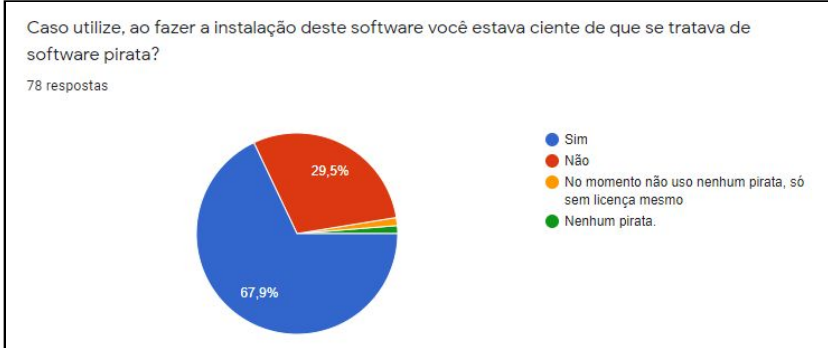

Figura 6 - Ciência dos respondentes sobre a pirataria do software no momento da instalação.

Mais uma vez, observa-se que, apesar de saber o que são softwares piratas, a maior parte dos respondentes $(67,9 \%)$ estava ciente desta condição no momento da instalação do software em seu dispositivo. 29,5\% respondeu que não tinham esta ciência, e o restando disse que não utiliza software sem a devida licença.

$O$ fato de não ter ciência de que um software pirata foi instalado no computador pode ocorrer quando os profissionais responsáveis pela manutenção dos equipamentos não fornece esta informação. Neste sentido, a questão seguinte aborda a conduta dos profissionais de tecnologia sobre a informação de uso de softwares piratas, conforme apresenta a Figura 7.

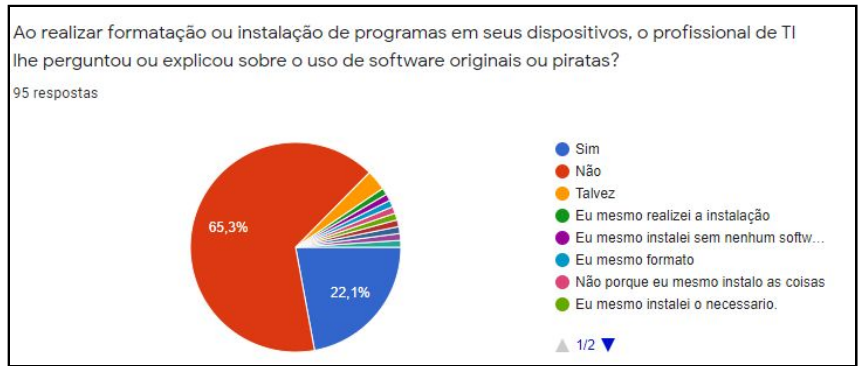

Figura 7 - Conduta profissional na instalação de softwares

Como podemos ver na Figura 7, mais da metade das pessoas respondeu que não foram informados pelos profissionais sobre o uso de softwares piratas no momento da manutenção, 65,3\% indicaram que foram informados pelo profissional, alguns indicaram que talvez tenham sido informados, e alguns respondentes indicaram também que eles mesmos realizaram a instalação dos softwares piratas, e apenas duas destas 100 respostas diz que faz o uso apenas softwares livres.
Tendo sido apresentado no corpo do formulário também informações sobre os riscos de uso de softwares piratas, questionou-se também se os respondentes tinham ciência destes riscos, conforme demonstra a Figura 8.

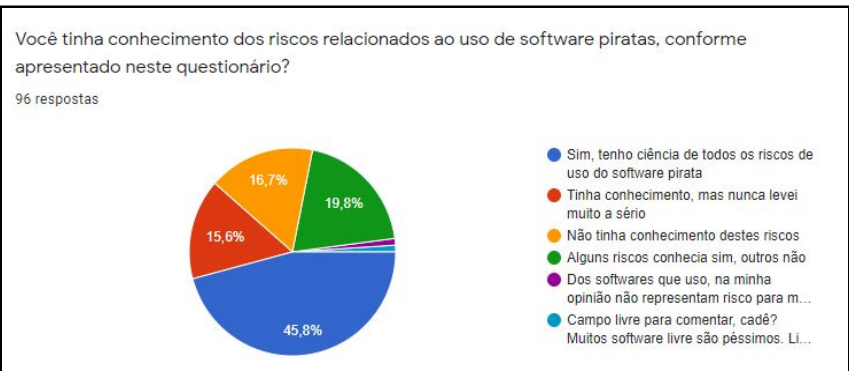

Figura 8 - Ciência dos respondentes sobre os riscos de uso dos softwares piratas.

$45,8 \%$ diz ter ciência dos riscos, $15,7 \%$ diz que tinha conhecimento porém nunca levou a sério, outros $16,7 \%$ informa que não possuía conhecimento sobre esses riscos e outros 19,8\% informaram que conhecia alguns riscos, enquanto outros não. Um dos respondentes manifestou também que não acredita haver risco no uso dos softwares piratas instalados, e um manifestou sua avaliação negativa de alguns softwares livres.

Finalizando o questionário, questionou-se se os respondentes possuem a intenção de utilizar softwares livres, e as respostas podem ser visualizadas na Figura 9.

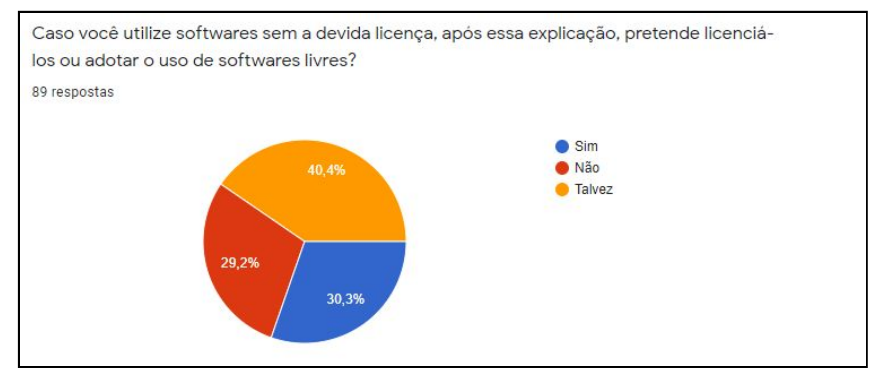

Figura 9 - Intenção de uso de softwares livres

As respostas indicam que apenas $30,3 \%$ está disposta a mudar para softwares livres e $40,4 \%$ indica que talvez mudaria, o que é positivo e demonstra a possibilidade de uma mudança de cultura. No entanto, 29,2\% dos respondentes diz que não pretende utilizar softwares livres.

\section{CONCLUSÃO}

Os computadores estão por todo lado e cada vez mais fazem parte do nosso dia-a-dia, realizando tarefas importantes para nós. Para que tarefas sejam executadas são necessários softwares, que permitem desde atividades simples até tarefas mais complexas. O uso de software livre é uma opção muito recomendada, sendo que atualmente existem softwares para as mais diversas funções e atividades, com desenvolvimento ativo da comunidade de profissionais desenvolvedores, além de facilitar para programadores pois possui cópia e distribuição sem restrições.

Por meio das respostas obtidas no questionário, identifica-se que há uma necessidade de mudança de cultura 
por parte da população regional abrangida pela pesquisa, pois muitos ainda fazem pouco caso dos aspectos legais e de segurança envolvidos no uso de softwares piratas, observando apenas a vantagem financeira obtida com a pirataria dos softwares.

Acredita-se que esta mudança de cultura pode ocorrer por meio da formação básica dos cidadãos, em seu período de escolarização. No entanto, algumas escolas não possuem componentes específicos de informática, por vezes motivada pela falta de infraestrutura básica, ou em alguns casos deixa de abordar as possibilidades de uso do software livre por falta de informação dos próprios professores, de forma que a cultura de uso de softwares comerciais se replica. Isso aponta para novos estudos e ações a serem realizados no campo da educação em tecnologias nas escolas e na formação de professores.

\section{Agradecimentos}

À instituição Centro Universitário FAI, que por meio de bolsa do Programa de Iniciação Científica (PIC) proporcionou o contato da acadêmica com a pesquisa científica por meio da realização deste trabalho.

Gostaria de estender meus agradecimentos à professora Juliane Colling por ter orientado e me incentivado ao longo desta pesquisa científica.

\section{REFERÊNCIAS}

BAGUETE. Pirataria: Guerra em Santa Catarina.

Disponivel em:

https://www.baguete.com.br/noticias/software/29/01/200

9/pirataria-guerra-em-santa-catarina. Acesso em: 28 set

2020.

BIEGER, Roger dos S. Pirataria em Ambientes

Corporativos. Revista Conexão, n.6, v.1, 2018.

Disponível em:

$<$ http://revista.faifaculdades.edu.br/index.php/conexao/a

rticle/view/526/331>. Acesso em 04 set. 2019.

BRASIL. Lei no 9.609 de 19 de fevereiro de 1998. Lei do software. Diário Oficial da União, Brasília,DF, 19 de fev. de 1998. Disponivel em:

http://www.planalto.gov.br/ccivil_03/leis/19609.htm.

Acesso em: 26 set. 2020.

BSA THE SOFTWARE ALLIANCE. Não adianta

disfarçar, isso não vai dar certo. Disponivel em: http://www.denunciesoftwareilegal.org.br/. Acesso em: 28 set. 2020 .

CONSTANCIO, JR. K. Software Livre X Software Pagouma Alternativa à Utilização de Software Pirata: Um Estudo na Escola Municipal do Município de Barra do Guarita - RS. Monografia (Tecnólogo de nível superior em Gestão da Tecnologia da Informação) - Faculdade de Itapiranga, Itapiranga, 2013.
MAIS DADOS DIGITAL. Pirataria de softwares é crime e causa prejuizo bilionário em todo o mundo. Disponível em:

https:/www.maisdados.com.br/pirataria-de-softwares-ecrime-e-causa-prejuizo-bilionario-em-todo-o-mundo/. Acesso em 12 nov. 2020.

OKUYAMA, F. Y.; MILETTO, E. M.; NICOLAO, M. Desenvolvimento de Software I. Conceitos básicos. Porto Alegre: 2014.

OLHAR DIGITAL. Entenda o ciberataque que afetou mais de 200 mil PCs em 150 países. Disponível em: https://olhardigital.com.br/especial/wannacry/. Acesso em: 29 set. 2020.

ORRICO, JR, Hugo. Pirataria de Software. $2^{\mathrm{a}}$ ed. São Paulo: 2004.

SOMMERVILLE, Ian. Engenharia de software. 9.ed. São Paulo: Pearson Education do Brasil, 2011

TECHSOUP. 6 riscos da instalação de um software pirata para sua empresa ou organização. Disponível em: https://www.techsoupbrasil.org.br/6-riscos-da-instalacao -de-um-software-pirata-para-sua-empresa-ou-organizaca o. Acesso em: 26 set. 2019. 